\title{
Miradas antagónicas del turismo en Argentina, una revisión sobre Bariloche y las guías de turismo del peronismo (1945-1955)
}

\author{
Antagonistic perspectives of tourism in Argentina, a review \\ about Bariloche and the Peronist's tourism guides
}

\author{
Maia Vargas \\ Universidad Nacional de Buenos Aires, Argentina \\ Paula Gabriela Núñez \\ Universidad Nacional de Río Negro, Argentina
}

DOI: https://doi.org/10.25032/crh.v6i10.7

Recibido: $22 / 3 / 2020$

Aprobado: 27/5/2020

Resumen: El turismo en Argentina ha tenido un clivaje estructural durante el peronismo histórico (1946-1955), observado por una extensa bibliografía. El presente trabajo busca revisar la heterogeneidad presente en la mirada y política turística diseñada por el gobierno peronista a partir de analizar la construcción de la imagen del turismo argentino en un caso particular: las imágenes de San Carlos de Bariloche presentes en tres guías de turismo, las guías Peuser de 1945, 1950 y 1955, desde las cuales se analizarán rupturas y continuidades a partir del modo que es presentado Bariloche a lo largo de esos años y en comparación respecto de la representación de otros dos sitios emblemáticos: Córdoba y Mar del Plata.

Palabras Clave: Bariloche, Córdoba, Mar del Plata, Turismo.

\begin{abstract}
Tourism in Argentina has had a structural cleavage during historical Peronism (1946-1955), as observed by an extensive bibliography. This paper seeks to review the heterogeneity present in the viewpoint and tourist policy designed by the Peronist government by analysing the construction of the image of Argentine tourism in a particular case: the images of San Carlos de Bariloche present in three tourist guides, the Peuser guides of 1945, 1950 and 1955 . These guides will analyze the breaks
\end{abstract}


and continuities in the way Bariloche is presented throughout those years and in comparison with the representation of two other emblematic sites: Córdoba and Mar del Plata.

Key words: Bariloche, Córdoba, Mar del Plata, Turism.

\section{Introducción}

Este trabajo busca hacer una revisión de la estética del turismo a partir de mostrar la diversidad en el reconocimiento territorial, , aún en un período de fuerte incidencia institucional, como fue el peronismo histórico. Para ello analizamos la diversidad de miradas diseñadas por el gobierno peronista a partir de revisar la construcción de la imagen de San Carlos de Bariloche en tres guías de turismo, las guías Peuser de 1945, 1950 y 1955, de las cuales se analizarán algunas rupturas y continuidades a partir del modo en que es presentado Bariloche a lo largo de esos años. Asimismo se realizará una comparación respecto de la representación de otros dos sitios emblemáticos, Córdoba y Mar del Plata. Nuestro objeto no es analizar el turismo social o profundizar en el análisis de las prácticas, aunque en parte dialoguemos con estos marcos que cuentan con antecedentes analíticos extensos. ${ }^{1}$ Lo que buscamos es hacer un análisis desde la teoría estética que permita avanzar en el modo en que antagonismos y diversidades se presentan en una misma compilación.

El turismo en Argentina ha tenido un clivaje estructural durante el peronismo histórico (1946-1955), observado por una extensa bibliografía. ${ }^{2}$ Sin embargo, hay aspectos territoriales que no pueden desmerecerse. Si bien, como señalaba el eslogan acuñado donde el peronismo «conocer la Patria es un deber» (Troncoso y Lois, 2004, 282), la patria estaba muy lejos de ser un espacio uniforme, tal como lo evidencian los

\footnotetext{
${ }^{1}$ Por ejemplo, en Bessera, E. «Exequiel Bustillo y la gestión de los Parques Nacionales. Una aproximación a su concepción de las fronteras como áreas naturales protegidas». En Pedro Navarro y Walter Delrio (eds.). Cultura y espacio: Contribuciones a la diacronización del corredor Norpatagonia Araucanía (pp. 115-125). Argentina: UNRN, 2011.

${ }^{2}$ Entre otros puede mencionarse Claudia Troncoso y Carla Lois, «Políticas turísticas y peronismo. Los atractivos turísticos promocionados en Visión Argentina (1950)». Pasos: Revista de Turismo y Patrimonio Cultural, Vol. 2, n. ${ }^{\circ}$ 2, pp. 281-294. 2004, y Melina Piglia y Elisa Pastoriza, «La construcción de políticas turísticas orientadas a los sectores medios durante el primer peronismo: Argentina. 1946-1955». Licere, Belo Horizonte, Vol. 20, N.ํ 1, mar. 2017: 411-452.
} 
estudios que dan cuenta de las particularidades políticas en los contextos administrativos provinciales (Macord y Tcach 2003).

Adoptamos las guías Peuser, como corpus central para el análisis gráfico, por su relevancia social, y por pertenecer a una editorial especialmente cercana a la administración nacional peronista, en tanto fue el ámbito en donde se publicaron la mayor parte de los textos más emblemáticos del gobierno. 3 El peronismo hace del ocio una política de estado, y en estas guías se representa gráficamente la mirada que se establece sobre los espacios definidos para el turismo en todo el territorio nacional.

La propuesta analítica cruza antecedentes de estudios sobre el turismo en el peronismo con la teoría de estética. A los antecedentes ya citados sobre turismo y peronismo, sumaremos estudios regionales relativos a Bariloche y el Parque Nacional Nahuel Huapi. La comparación con otros centros turísticos no tendrá antecedentes equivalentes por motivos de espacio.

Dado que el foco es la pregunta por la construcción estética, en relación con esta, tomaremos autores como John Berger y su propuesta de una mirada contextualizada de las imágenes en su libro Modos de ver (2013), Roland Barthes, con su enfoque semiótico sobre la fotografía $(1990,1986)$ y las relaciones entre texto e imágenes y Walter Benjamin (2010) con su concepto de «estetización de la política» para dar cuenta de la importancia fundamental de los elementos estéticos en la política. iEstos autores nos permitirán para analizar las relaciones entre elementos estéticos que aparecen en las guías Peuser y sus contextos de lectura. En este sentido, problematizamos las guías, fundamentalmente, desde sus imágenes, poniéndolas siempre en relación con los elementos estéticos que las rodean y complementan. Tomamos como imagen el diseño editorial y la tipografía seleccionada. Reconoceremos en sus fotografías, en

\footnotetext{
${ }^{3}$ Tal como se puede observar en Noemí Girbal Blacha, En la Argentina peronista «Los únicos privilegiados son los niños» (1946-1955). La doctrina desde la Biblioteca Infantil «General Perón». 2015. Disponible en: http://www.ehu.eus/ojs/index.php/HC/article/view/14145 y Gabriela Cruder, «La biblioteca infantil General Perón: una propuesta comunicacional para la formación ciudadana de los niños», Revista Questión, 2011. Disponible en:

http://perio.unlp.edu.ar/ojs/index.php/question/article/view/1224. Cabe destacar que, entre 1945 y 1944, a través del Consejo Nacional de Educación, el Ministerio de Cultura y más tarde la Fundación Eva Perón impulsaron la publicación de unas serie de libros históricos dirigidos a los niños, la colección Biblioteca Infantil General Perón, publicada en el año 1949 por Peuser. Esta colección estuvo compuesta por doce títulos, entre los cuales figuran Cuentos heroicos argentinos, El niño en la Historia argentina, Cuentos del 17 de Octubre, Historia de los gobiernos argentinos, Una mujer argentina: Doña María Eva Duarte de Perón y el más conocido: La razón de mi vida La promoción editorial del gobierno peronista es uno de los aspectos más recorridos del gobierno
} 
sus mapas y diseños, en su modo de escritura las claves para la definición de la identidad de la Patagonia Andina. En el caso específico de los mapas, tomaremos los aportes de Carla Lois (2015) quien nos invita a sospechar de ellos y mirarlos, no solo como objetos científicos sino también artísticos. Como resultado observaremos de qué manera, en el diseño de una guía de turismo, se representan las regiones de nuestro país que marcan apropiaciones diferentes y que desde la estética señalan integraciones desiguales.

Reconoceremos una visión europeísta de la historia (y de la geografía) impactando en la estética, lo cual resulta especialmente claro en la presentación turística de los Parques Nacionales, que no está presente en otros espacios. Observaremos cómo este reconocimiento reforzó un dominio no solo simbólico sino económico, donde los relatos sobre las zonas centrales subordinan a lo construido como periferia.

\section{Mapas e índices de turismo}

Para analizar los mapas presentes en las guías Peuser de estos años tomaremos las consideraciones de Lois (2015) quien considera al mapa como un material no solo científico sino artístico. La autora define al mapa como «... toda representación gráfica que facilita el conocimiento espacial de las cosas, conceptos, condiciones, procesos o eventos que conciernen al mundo humano» (Lois 2015 1). Observa cómo, muchas veces, se toma al mapa desde una concepción reduccionista y limitada, lo mismo sucede con la fotografía. Ambos suelen ser considerados como herramientas transparentes pero, como varios autores han demostrado, esta concepción genera un obstáculo epistemológico para el tratamiento crítico de las imágenes, ya sean mapas o fotografías, ambos son objetos culturales y por lo tanto arbitrarios y no realistas, neutrales o científicos como suele creerse. La autora insiste «todavía sigue siendo tediosamente necesario afirmar que a veces los mapas «mienten» (Monmonier 1996) o que no tienen ningún vínculo con las «geografías reales» (Lois: 2015, 4).

El análisis del clivaje en el turismo propiciado por el peronismo ha dejado varias conclusiones. Pastoriza y Pedetta (2009), señalan una diferencia territorial en el surgimiento del turismo. Sus estudios indican que «El esparcimiento en los lugares de veraneo como uso del tiempo libre figuró en el programa del peronismo con los planes 
de vacaciones y excursiones populares. El proyecto abarcó dos espacios claramente definidos: las áreas marginales bajo la tutela de Parques Nacionales (Cataratas del Iguazú y la zona del Lago Nahuel Huapi) y los ámbitos ya elegidos por las élites y las clases medias. Mientras los primeros emergieron lentamente, el centro de las promociones estuvo centrado en la ciudad de Mar del Plata y las sierras de Córdoba.» (Pastoriza y Pedetta 2009 3).

Las imágenes elaboradas dentro de las guías de turismo analizadas muestran cómo se fue complejizando la mirada sobre el territorio desde el mapa que, en cada guía analizada, presenta los atractivos turísticos en el país.

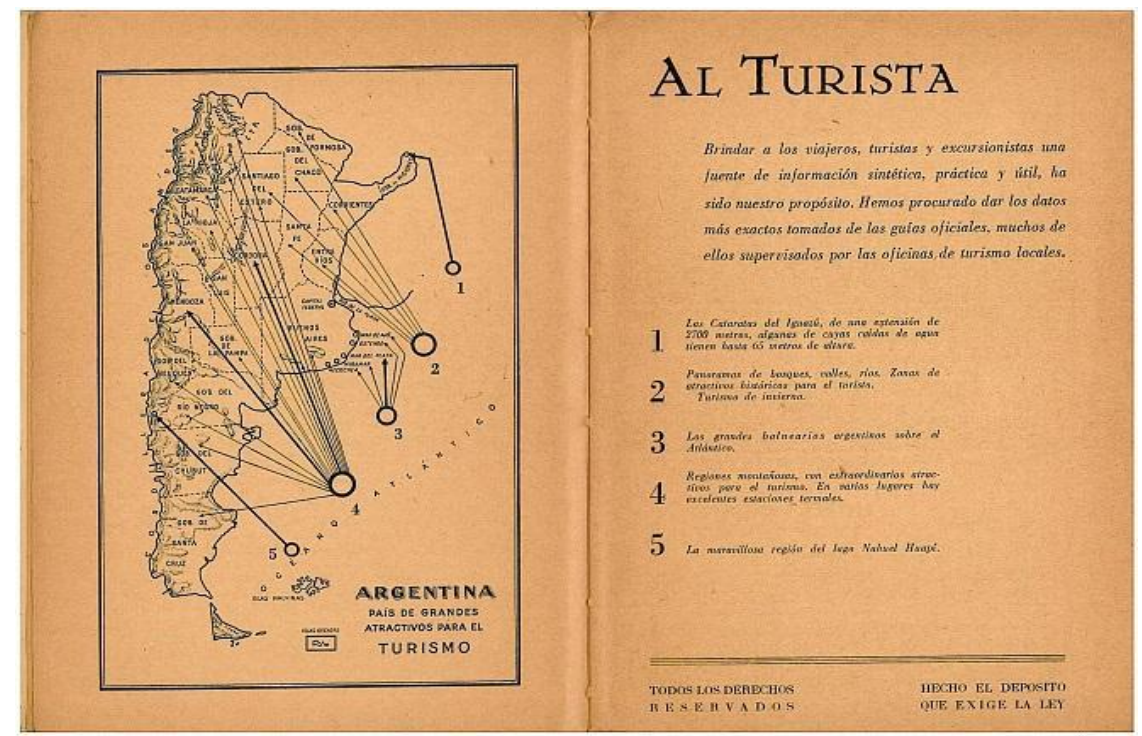

Fig. 1: Mapa guía Peuser, 1945, 6.

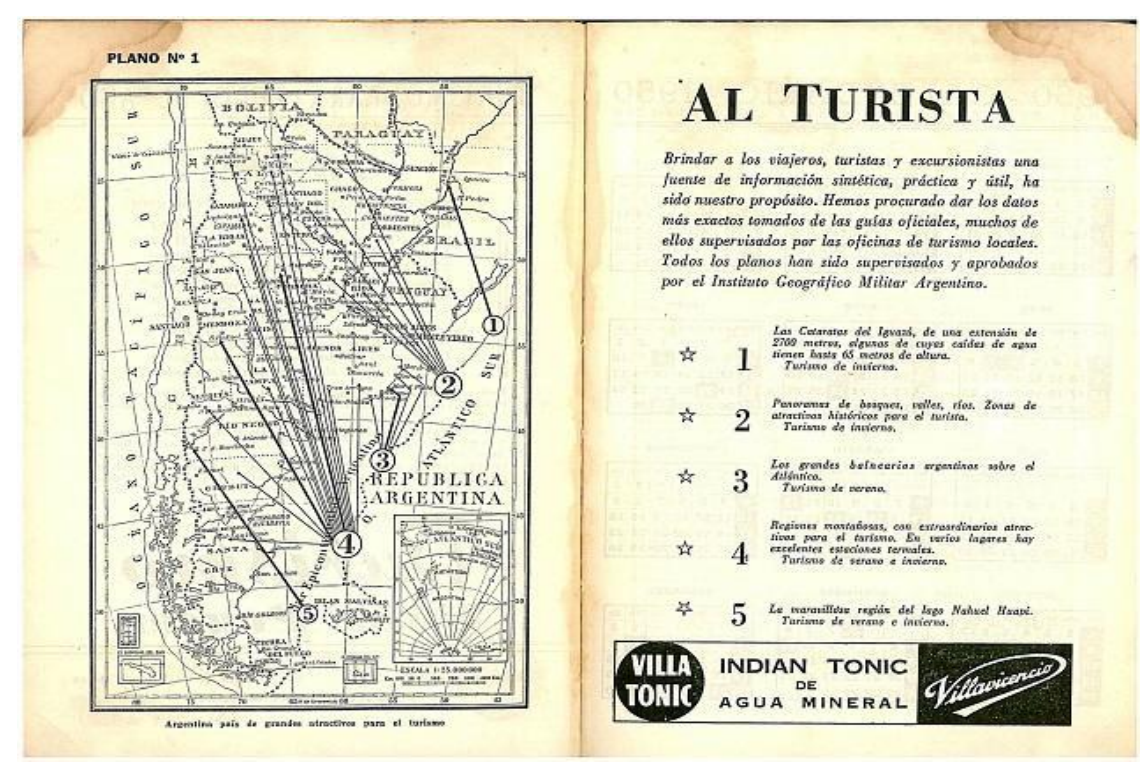

Fig. 2. Mapa guía Peuser, 1950, 3. 


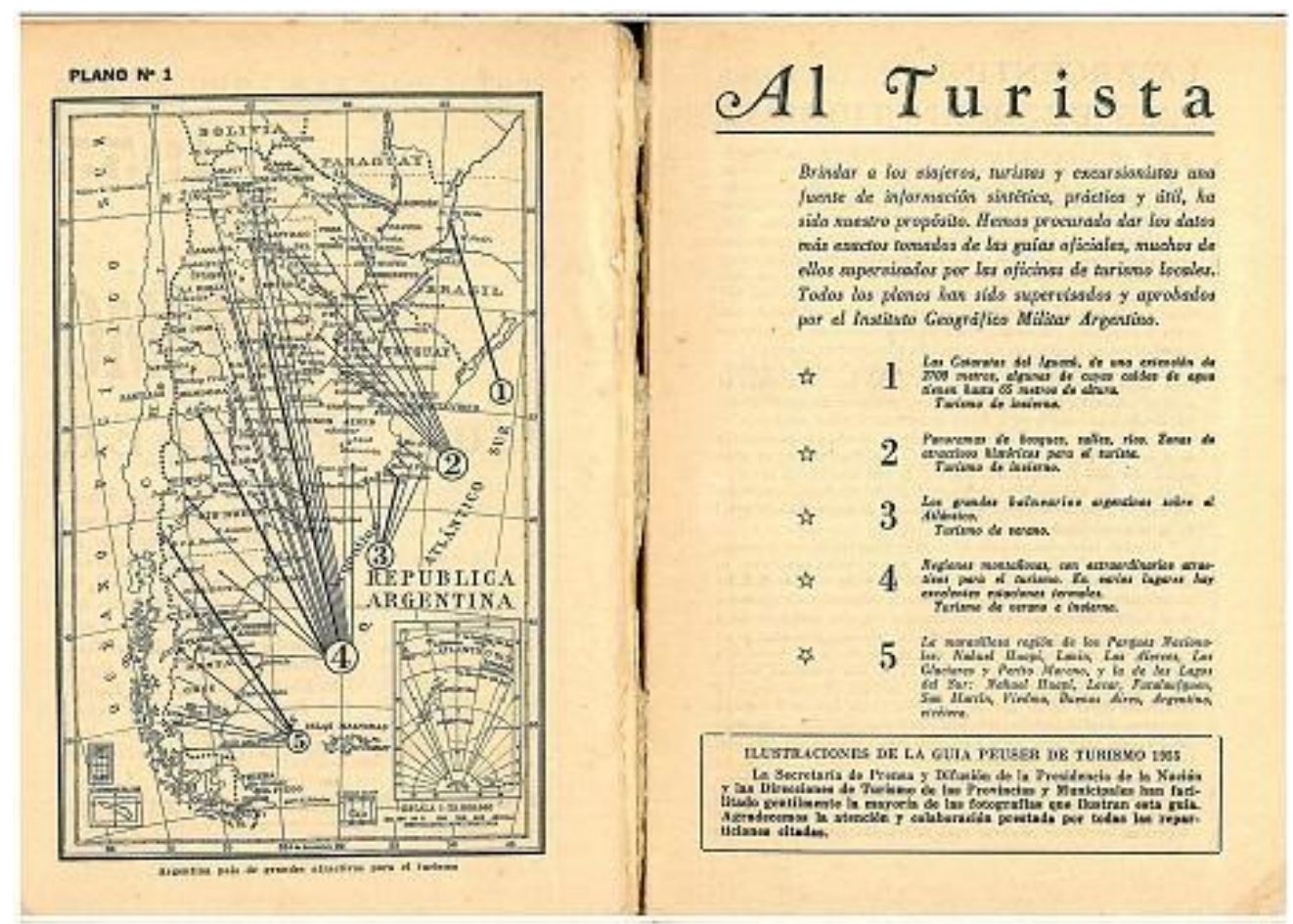

Fig. 3. Mapa guía Peuser, 1955, 1.

Una mirada sobre estas nos muestra la cantidad de líneas que engrosan las áreas 2 y 4. Básicamente centro, noroeste y parte del litoral y norte se marcan con muchas más líneas. El sur recién se complejiza tras 1950, cuando a la «maravilla de la región del Nahuel Huapi» se suman las referencias a otras regiones. Iguazú, y la zona de playas de Buenos Aires, no se amplían en estos años.

Siguiendo a Pastoriza (2013), encontramos una temporalidad diferenciada en las políticas de turistificación, que se replica en las representaciones. En este punto no es menor la forma en que el propio peronismo presenta al país. Para enmarcar las imágenes de las guías Peuser en la mirada peronista incorporaremos una referencia al texto «La nación argentina, libre Justa Soberana» (1950). Este texto resume en forma gráfica las propuestas y alcances del gobierno de Perón hasta la fecha. Fue editado por Peuser y presentado en el salón de dicha editorial (Cicalese 2018). Cicalese señala que «El justicialismo se empeñaba en concebir un régimen visual y textual con potencia simbólica; en ese derrotero podemos situar conceptualmente al atlas como uno de los grandes aportantes a ese plan maestro» (Cicalese 2018 3). Ni Peuser, como los artesanos gráficos responsables 
en traducir las ideas a imágenes, ni el turismo como tema, quedan fuera. Lo que no es obvio es que, a pesar del discurso de equidad, el territorio en su conjunto sea reconocido en forma equiparable.

La reflexión sobre las imágenes del turismo, y su inscripción en el país, no pueden despegarse de las del desarrollo del país. En estas, las referencias a «la nación argentina...» resultan centrales.

Una primera imagen para verlo es la figura 4: los nueve pilares sobre los que descansa la futura grandeza de nuestra patria. En ella puede verse el contraste de la nación previa, la del embudo que se llevaba las riquezas del país. Pero los nueve nuevos pilares tienen un problema, al menos para la Patagonia. En contra de la producción reconocida en Santa Fé, Paraná, Rosario; Resistencia, Corrientes, además de centros históricos como Buenos Aires; Córdoba; Mendoza y Tucumán; los centros patagónicos que aparecen nombrados refieren a elementos que se sacan para actividades que se desarrollan en otros lugares. Comodoro Rivadavia y Confluencia son sitios de extracción: el primero de petróleo, el segundo de energía eléctrica y petróleo. No hay una sociedad que hace y produce, hay algo que se saca, y en esto la Patagonia resulta integrada en forma diferente al resto, pues nada de lo que se hace se toma como de valor para la nación. 


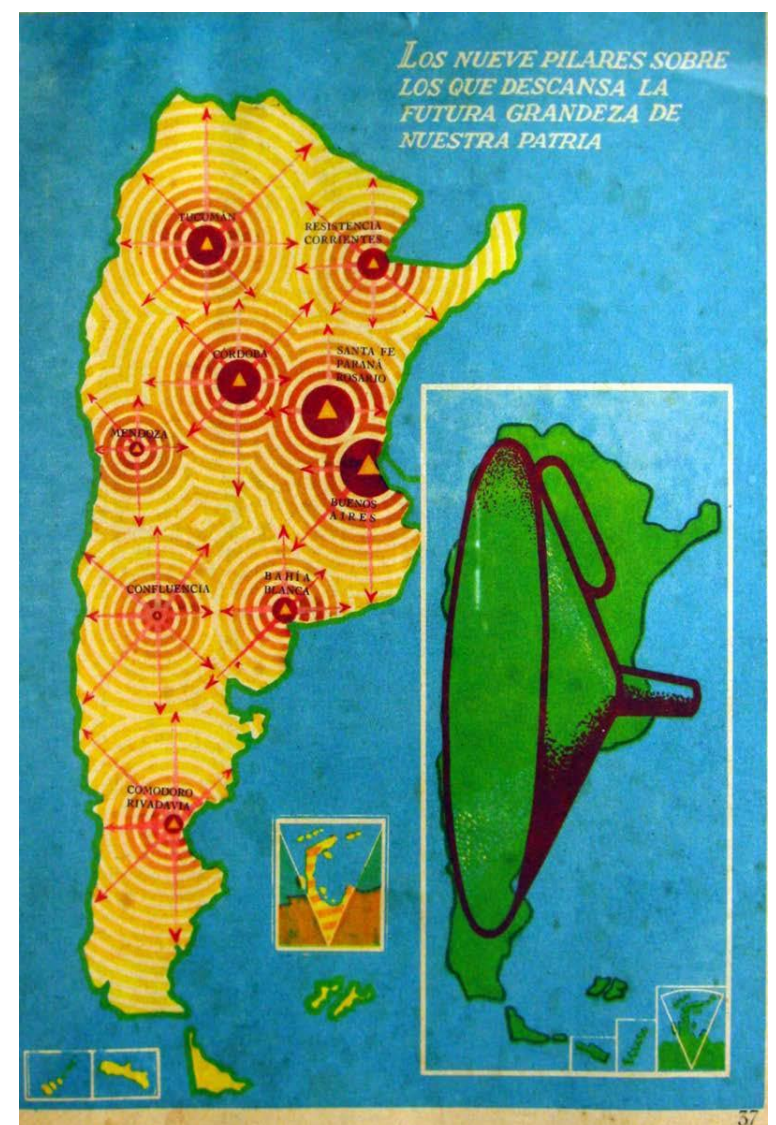

Fig. 4. Gráfico: «La nación libre justa soberana», 1950, 32.

Esto se replica en el cambio que se grafica en términos de turismo. El gráfico 3 (Fig. 5) muestra cómo se representa el incremento turístico entre 1943 y 1949. En él se observa cómo hay un vacío en las flechas del noroeste que se van llenando en las figuras que representan los años subsecuentes. El detalle de los números se muestra en un gráfico que representa la forma en que se incrementan los números del turismo yfue elaborado con los datos del Atlas. Destaca en él el antecedente y salto de Córdoba y Mar del Plata, así como el avance de Salta y el noroeste en términos de turismo. 


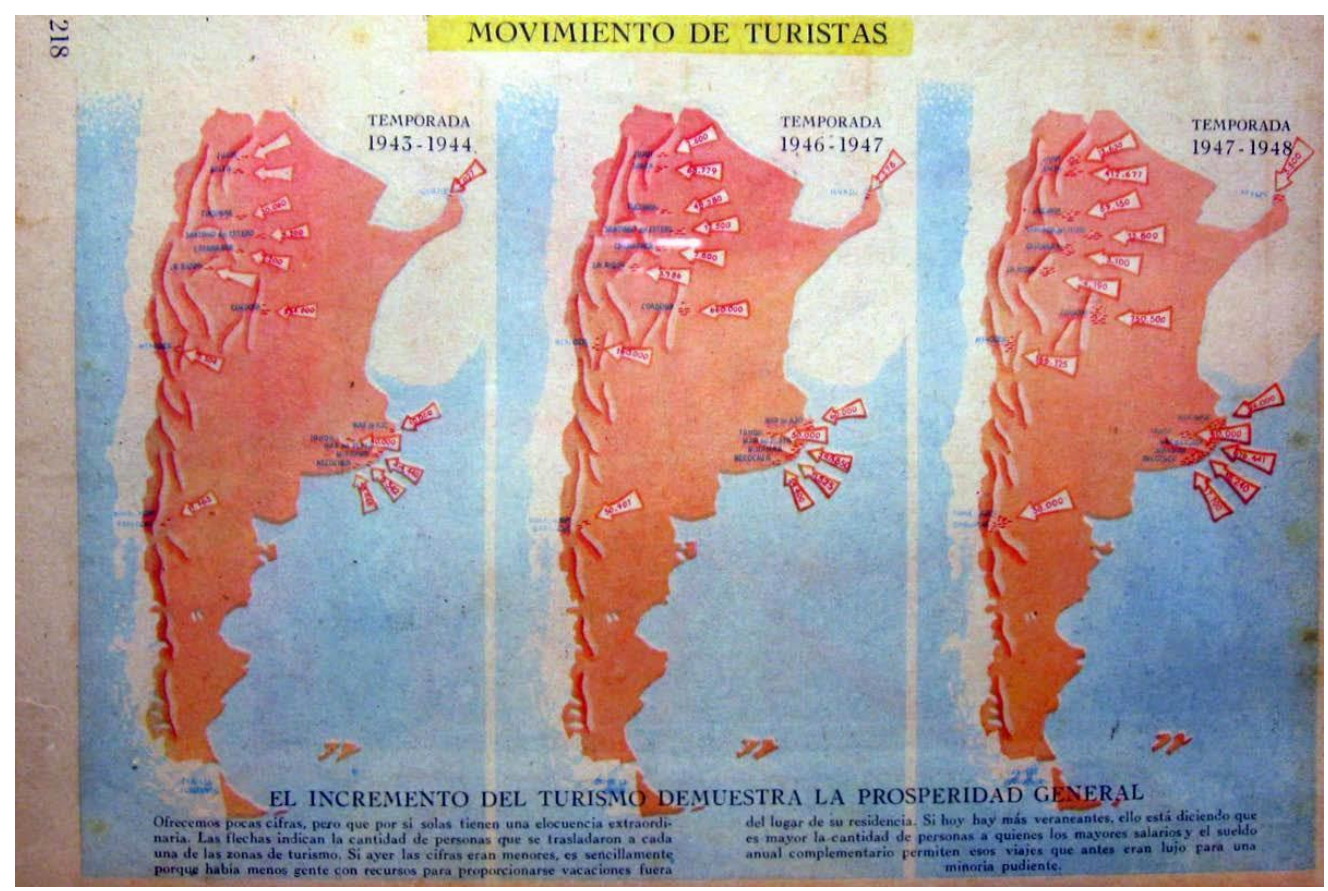

Fig. 5: «La nación libre justa soberana», 1950, 213.

Estas cantidades muestran lo que los mapas de las guías de turismo ya indican, y que reproduce el esquema territorial de los pilares de la grandeza del país, que la región del Nahuel Huapi, a pesar de ser relevante, tiene un reconocimiento diferente y subalterno respecto del resto del territorio. Asimismo, refleja lo ya encontrado por Pastoriza, y el conjunto de autores que ha indagado en el turismo social del peronismo. Mar del Plata y Córdoba son los dos principales centros.

Lois propone tomar la inestabilidad propia de la imagen cartográfica en clave positiva. Aceptar la flexibilidad del objeto cartográfico nos abre a múltiples posibilidades para analizar «... cómo participan los mapas en nuestras experiencias y concepciones sobre el espacio, la historia, la sociedad y el mundo» (Lois 2015 10). Desde esta propuesta epistemológica podríamos decir que cada mapa responde al «modo de ver» (Berger 2013) de su contexto. Una extensa bibliografía ha dado cuenta de la integración desigual de la Patagonia, reforzada durante el peronismo histórico.4

\footnotetext{
4 Algunos ejemplos son: Navarro Floria, «Territorios marginales: los desiertos inventados latinoamericanos. Representaciones controvertidas, fragmentadas y resignificadas.» En Los desiertos en la historia de América, una visión multidisciplinaria. Dení Trejo Barajas, coordinadora. Morelia, Michoacán, México, 2011; Paula Núñez, «The peronist incomplete reconstruction of the border: An analysis of the Nahuel Huapi región», Argentina (1946-1955). Estudios Fronterizos 16 (31): 56-73. 2015; G. Iuorno, «La provincialización de Río Negro. Interregno y conflicto de intereses nacionales y locales», en M. Ruffini y R. F. Masera (coords.) Horizontes en perspectiva. Contribuciones para la historia de Río Negro, 1884-1955, (pp. 391- 405), Viedma, Legislatura de la Provincia de Río Negro, 2007; M.Ruffini, Peronismo, «Territorios Nacionales y ciudadanía política. Algunas reflexiones en torno a la provincialización». Revista Avances del Cesor, N. ${ }^{\circ}$ 5, pp. 132-148, 2005; M. Arias, «Tensiones en los
} 
Lo que buscamos explorar en la siguiente sección es como el propio imaginario territorial permite el deslizamiento de la desigualdad política al reconocimiento del propio paisaje.

\section{Las guías de turismo}

Las guías de turismo Peuser contienen dentro de sí distintos tipos de materiales estéticos: fotografías, dibujos, mapas, tipografía, publicidades, organizados de cierta forma. John Berger (2013) realiza una teoría sociológica de la imagen, donde destaca la importancia del «modo de ver» que es construido socialmente en determinados contextos. Es importante entender el contexto de las imágenes en un doble sentido: por un lado su contexto histórico-político, y por otro el contexto inmediato que rodea la imagen. Ya que toda imagen se halla siempre en relación con otros elementos. Toda imagen posee determinaciones materiales que modifican sus lecturas. «La significación de una imagen cambia en función de lo que uno ve a su lado o inmediatamente después. $\mathrm{Y}$ así, la autoridad que conserve se distribuye por todo el contexto en que aparece» (Berger 2013 37).

Los distintos materiales estéticos presentes en las guías Peuser van construyendo determinados imaginarios sobre este territorio. Estas guías turísticas pueden ser ejemplo de una estética institucional, que en este caso pertenecen al ámbito privado no estatal, pero con una financiación mixta. A través de ellas buscamos reflexionar sobre la carga política de las imágenes sobre el territorio patagónico.

Nuestra propuesta es analizar tres guías (las de los años 1945, 1950, 1955) para a través de estos diez años del primer momento del peronismo, haciéndo énfasis en $r$ la construcción visual que se hace de este paisaje, entendiendo que eso implica una mirada política sobre este, y que habilita cierto vínculo del turista con el lugar descrito. Diversos estudios dan cuenta de la importancia que poseen las imágenes en el peronismo (Troncoso y Lois 2004). Walter Benjamin acuña el concepto «estetización de la política» (2010) para dar cuenta de la importancia fundamental que tuvieron los elementos estéticos durante el fascismo, especialmente en el manejo que se hace de las masas: los desfiles, la festividad de los deportes, los actos y manifestaciones masivas

debates parlamentarios en torno a la provincialización de los Territorios Nacionales durante el primer peronismo». Quinto Sol, N. ${ }^{14}$, pp. 103-124, 2010. 
organizados por el Tercer Reich en donde se hacía una utilización regresiva de la técnica ya que reponía prácticas culturales y las masas autoalienadas experimentaban, según Benjamin, un goce estético de primer orden, de este modo la belleza se vincula estrecha y peligrosamente a la guerra. Un ejemplo de esto son las películas realizadas por la cineasta alemana Leni Riefenstahl. En su película Olympia (1936) registra los Juegos Olímpicos de Berlín en la alemania nazi. Aquí se ven los usos de la técnica cinematográfica al servicio de la propaganda política. La contracara de la estetización de la política es la que Benjamin denomina «politización del arte».

En este marco, y salvando las distancias, consideramos que las guías de turismo son un objeto estético, entre muchos otros, que se pueden enmarcar dentro de los recursos propios de la estetización de la política que realiza el peronismo, así como el «modo de ver» (Berger 2013) particular que este tiene sobre el turismo. Las guías proporcionan ayuda para moldear expectativas y conductas de la futura experiencia del viajero, creando un marco para disfrutar de un lugar. A su vez actúan como prismas a través de los cuáles se puede ver al mundo, porque facilitan la formación de imágenes sobre ciertos lugares aún sin visitarlos. «... acentúan o discriminan aspectos del lugar de destino contribuyendo a la construcción del carácter de ese lugar y al conocimiento que el potencial viajero puede tener del mismo» (Picone 2013 200).

\section{Mar del Plata y Córdoba}

Elisa Pastoriza (2008; 2013) señala que Mar del Plata y Córdoba fueron el foco principal de la política turística del peronismo. Se destacan como áreas de disfrute cercano, con muchos accesos y servicios. Tienen un fuerte desarrollo previo, sobre el que se apoya la democratización que propone el peronismo.

Las guías Peuser, en las ediciones analizadas, los presentan como espacios vividos, llenos de gente. Córdoba se destaca por ser el lugar donde todo tiene una reminiscencia histórica. Tal es así que se recata el pasado precolombino. Las fotografías remiten a caminos, animales, construcciones de adobe o imágenes de embalses. Los textos hablan de sus museos, su conservatorio, sus «templos coloniales», su «patrimonio vivo» (Guía Peuser 1945 136). Estas son imágenes ya canónicas de esos espacios, que se difunden con fuerza en los años treinta: son lo pintoresco, opuesto al sublime de las cataratas o las montañas del sur (Silvestri 1999). 


\section{CÓRDOBA (*)}

LȦ REGIÓN DE LA ETERNA PRIMAVÈ̃RA<smiles>c1ccccc1</smiles>

ÓRDOBa y sus sierras - por la armonía de factores que atesora su admirable trilogía - constituye una región cuyo prestigio ha sobre. pasado ya los límites de la Argentina.

Tan loadas han sido las serranías de Córdoba, por plumas ágiles y espiritus selectos, que todo elogio podría parecer una redundancia. Definidas están, principalmente, por la armonía de factores que bien puede afirmarse como admirable trilogía: salud, belleza panorámica y comodidad sin esfuerzo alguno.

Cada trazo de Córdoba, cada lugar, monumento, paraje, camino, pueblo, iglesia o aledaño, encierra una reminiscencia histórica. Desde las viejas casonas con amplios patios y gárgolas talladas de la ciudad capital, hasta los pasos y laderas abruptas de los peñascales, tienen una apasionante historia que proviene muchas veces de mucho antes del coloniaje y la República, ya que hasta Tucumán y Córdoba llegaron en tiempos precolombinos, los pueblos migradores de la admirable civilización incaica.

(•) Véanae plano en colores y No 3.

Fig 6: Guía Peuser,1945, 131.

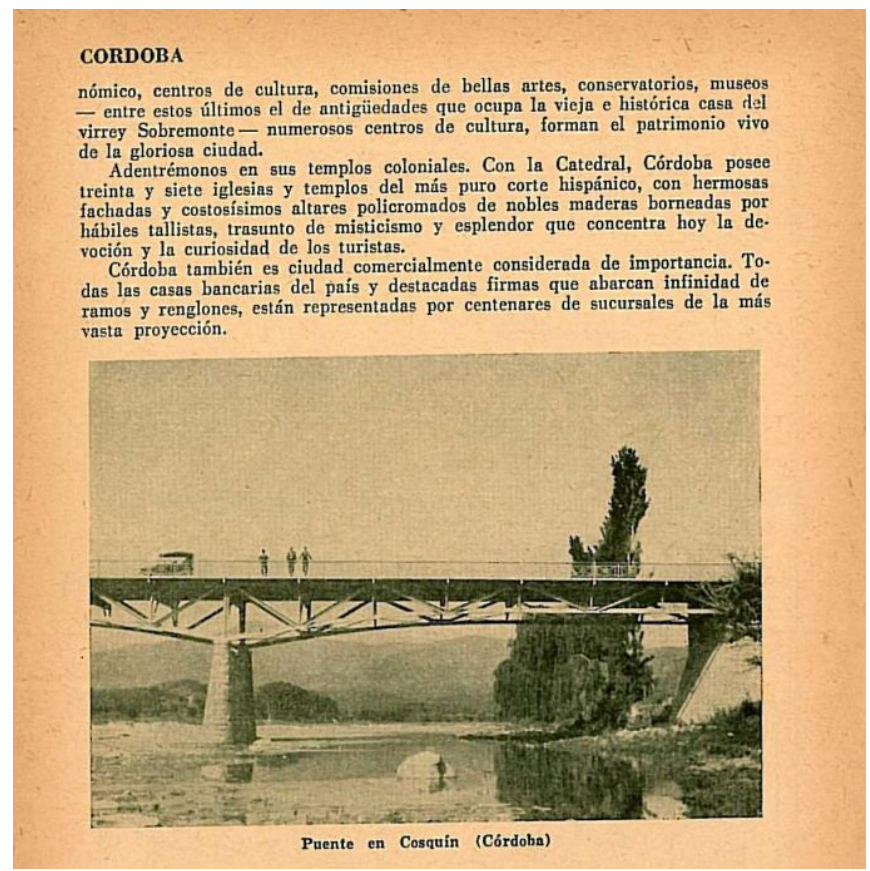

Fig 7: Guía Peuser,1945, 136. 


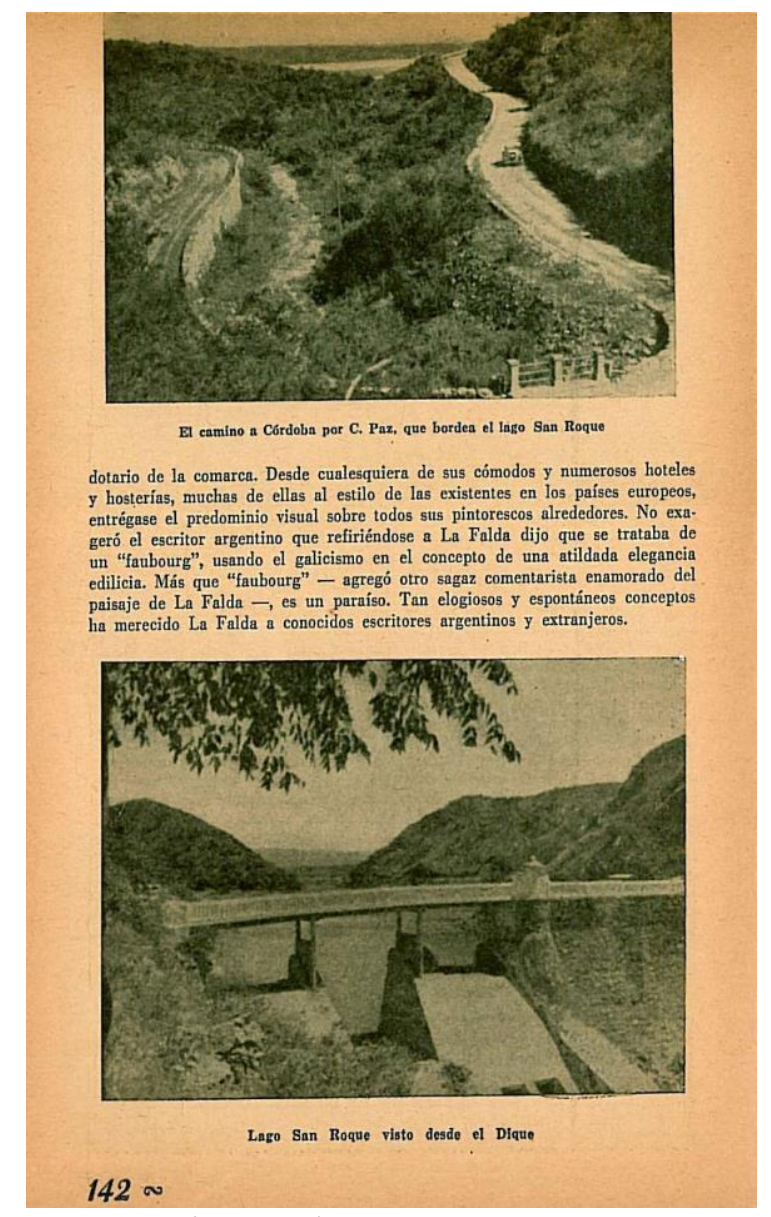

Fig 8: Guía Peuser,1945, 142.

Desde allí se abren descripciones similares, que hacen referencias al clima, a lo pintoresco del entorno y a las experiencias de paisajes. Córdoba es un centro con marcas propias y antiguas. Un espacio lleno de recorridos, donde la memoria nacional se presenta con materialidades que en sí resultan atractivos turísticos. Como su arquitectura «No exageró el escritor argentino que refiriéndose a La Falda dijo que se trataba de un "Faubourg", usando el galicismo en el concepto de una atildada elegancia edilicia5» (Guía Peuser 1945 142).

Mar del Plata tiene similitudes en tanto se presenta también como espacio vivido. Destacamos esto respecto del contraste que llevaremos adelante con la región del Nahuel Huapi.

En la guía de 1945, Mar del Plata se presenta como el primer balneario de América del Sur:

\footnotetext{
${ }^{5}$ Faubourg es un antiguo término francés que significa suburbio.
} 


\section{MAR DEL PLATA (*)}

El primer Balneario de la América del Sud (**)

T os viajeros que nos visitaron hace un siglo, conocieron a la después "Aldea Grande" bañándose en su propio río. Ahi no más, entre las 1 Aldea Grande los murallones del Fuerte, no tan cerca de Los Pozos, donde William Brown - el más glorioso de nuestros marinos y el más popular de nuestros guerreros - sostenía sus batallas navales a la vista de todo Buenos Aires. El refugio costanero de entonces - como quien dijera la rambla - era la vieja alameda que se extendia en unas pocas cuadras bacia el norte, ocupan. (*) Vóanse plano en colores y NQ 1. Mur del Plata.

Fig 9. Guía Peuser 1945, 37.

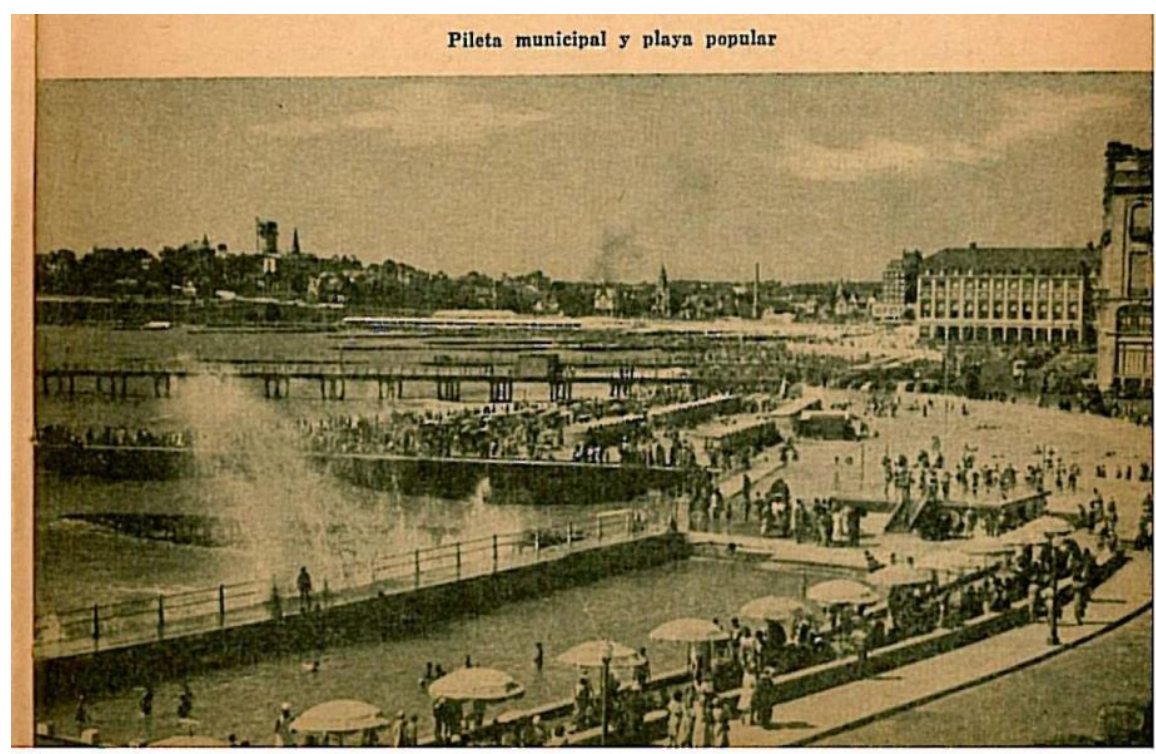

Fig 10. Guía Peuser, 1945, 39.

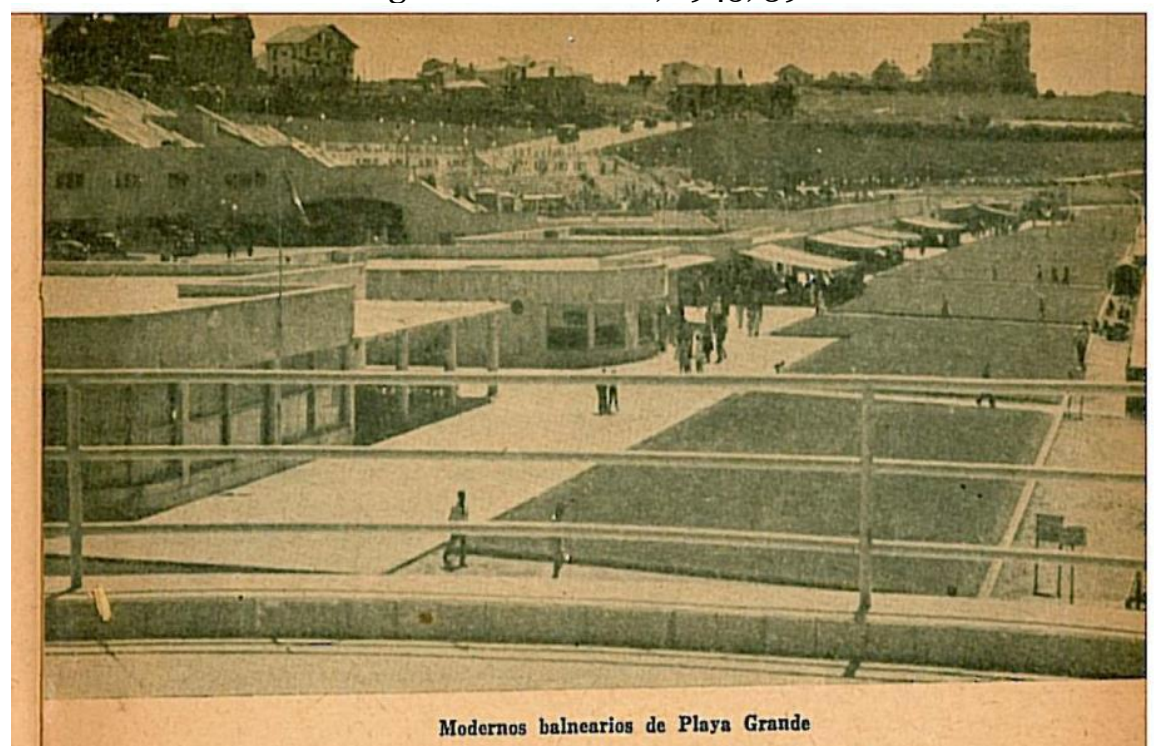

Fig 11: Guía Peuser, 1945, 41. 
En 1950, ya la referencia inicial alude a una alta sociedad que construyó un espacio que el peronismo reivindica como propio. «Esta hermosa e inigualada ciudad balnearia ha sido hecha en sus comienzos a base de corazón por la alta sociedad porteña, pavida de poseer centros de excepcionales condiciones para el veraneo. No podría adaptarse al círculo concéntrico formado por las riberas del río de La Plata, cuya fama de turbulento y caudaloso le fue otorgada por escritores y poetas» (Guía Peuser 1950 88).

En 1955, ya resuelta la resignificación, la retórica apela a la relevancia del balneario en el mundo.

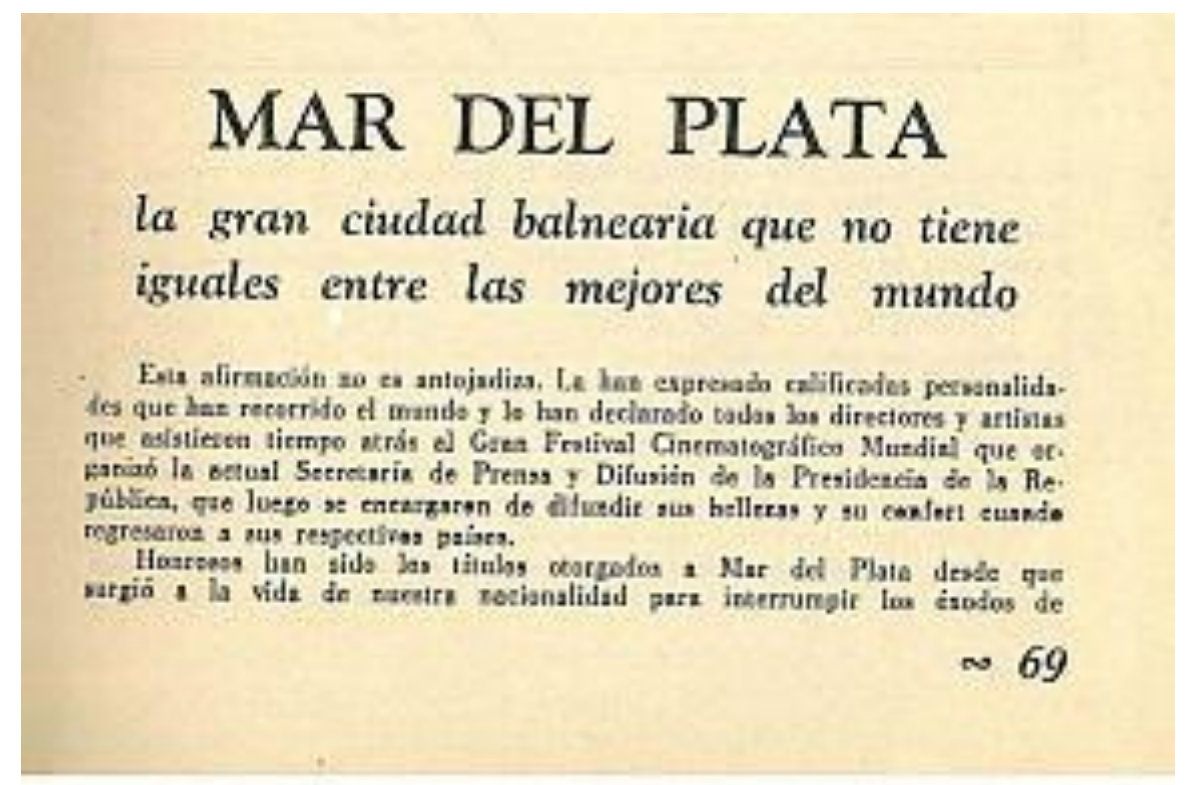

Fig 12: Guía Peuser, 1955, 69.

Estas ideas circulan en las tres presentaciones, el balneario desconocido que a fines del siglo XIX comenzó a crecer como espacio urbano, a la medida que fue creciendo el ocio. Como decíamos antes, no solo se trata de fotografías, sino también de las relaciones con los elementos que las rodean, como sus titulaciones y textos que las rodean. La relevancia del dato y adjetivación construyen la imagen visual de lo que se encuentra al abrir la hoja. Foto, textos, títulos, diseño y tipografía se cruzan. El peronismo disputa sentidos, y no es menor que se apropie de lo que entiende como un refugio de la alta sociedad. En 1950 elige esta mención para dar lugar a la presentación de las playas. En 1955 es el verano y sus servicios, especialmente el Gran Festival cinematográfico Mundial lo que se resalta. Las imágenes son elocuentes: grandes y 
cómodas urbanizaciones en playas llenas de gente. El mejor lugar para la costumbre de las vacaciones.

Así, los principales centros turísticos, son en los discursos gráficos y literales, espacios de una larga historia de urbanización, con pesos políticos propios y, fundamentalmente, habitados. Mar del Plata, más que Córdoba, es un sitio de disputa social. Córdoba es la referencia histórica. Ámbos son los marcos para repensar la representación del turismo en Bariloche.

\section{Bariloche, o el turismo de las áreas protegidas vacías}

Bariloche, como destino turístico, se asocia a la creación del Parque Nacional Nahuel Huapi, en 1934, y a la llegada de la punta de rieles que conectaba Buenos Aires con esta localidad, este mismo año. Es, así, un destino mucho más nuevo que los citados. Sin embargo tiene una característica que lo une a Mar del Plata, es un destino elegido por la alta sociedad (Núñez 2007).

El contraste que se plantea es en la representación. Bariloche, a pesar de estar urbanizado incipientemente desde 1895, y formalmente creado desde 1902, se presenta como un espacio vacío. Esto es, negando la propia población existente, tanto en términos de pueblos originarios como de la colonización posterior (Núñez, 2013). Esta paradoja ya ha sido recorrida por la historiografía local, ${ }^{6}$ lo que interesa en la presente reflexión es cómo impacta en el contexto específico del peronismo histórico.

Debemos indicar que un antecedente para nuestra reflexión es el artículo de Ángeles Picone (2013) que compara dos guías de turismo de 1938, una publicada por la Dirección de Parques Nacionales y otra de un privado, escrita por Adrián Patroni. Tomaremos su modelo de análisis aunque se dirija a guías distintas, pues muestra

\footnotetext{
${ }^{6}$ Algunos de los autores que la han revisado son L. Méndez y S. J. Muñoz, «Alianzas sectoriales en clave regional. La Norpatagonia argentino-chilena entre 1895 y 1920». En M. A. Nicoletti y P. Núñez (comps.), Araucanía-Norpatagonia: La territorialidad en debate (pp. 152-167). Argentina: IIDYPCA. 2013. y también Pedro Navarro Floria, «Territorios marginales...»2011., en E. Bessera «Exequiel Bustillo y la gestión de los Parques Nacionales. Una aproximación a su concepción de las fronteras como áreas naturales protegidas», en Pedro Navarro y W. Delrio (eds.). Cultura y espacio: Contribuciones a la diacronización del corredor Norpatagonia Araucanía, San Carlos de Bariloche, Universidad Nacional de Río Negro-Instituto de Investigaciones en Diversidad Cultural y Procesos de Cambio, 2011, (pp. 115125), y en Paula Núñez, «The peronist incomplete reconstruction...», 2015.
} 
como las guías editadas desde espacios estatales evidencian el discurso político antes que el espacio.

Picone muestra como las tempranas guías que analiza sirvan para dar cuenta del «proceso de construcción de nacionalidad en zona de frontera y sobre como aquellas ideas de lo que debía ser lo nacional se proyectaron en la relación entre el hombre y el paisaje...» (Picone 2013 212). Picone toma de Fortunato (2005) que la constitución del Parque Nacional, es una estrategia política, antes que ecológica, por lo tanto «Hacer turismo, desde la Dirección de Parques Nacionales, es mucho más que un simple disfrute, es la consolidación de una ciudadanía» (Picone 2013 214). Tomaremos esta afirmación para compararla con nuestras guías Peuser de años posteriores.

A diferencia del carácter argentino de Córdoba o Mar del Plata, la homologación del paisaje americano al europeo es la caracterización de Bariloche, que es presentado como la «Suiza argentina» que, como podemos ver, por ejemplo, en este extracto de la guía de 1945, se manifiesta desde el primer párrafo. Pero es una denominación que aparecerá en reiteradas ocasiones.

\section{Región de los Lagos del Sur(*)}

PAISAJES DE AGUA, DE NIEVE, DE PIEDRAS $Y$ DE BOSQUES

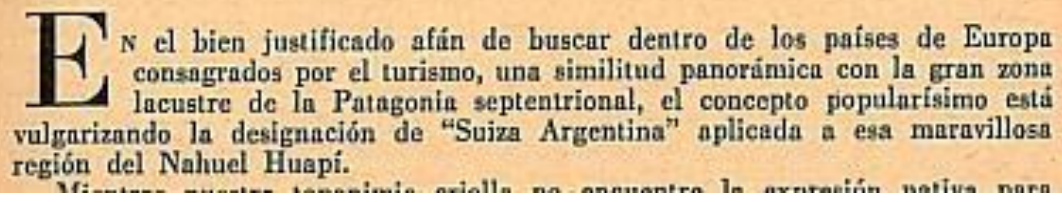

Fig 13: Guía Peuser, 1945, 311.

El segundo párrafo es dedicado a explicar por qué esta comparación es «ajustada»y «oportuna»y porque nuestra región es superadora de la europea. Es llamativa como la descripción que define a la naturaleza utiliza ciertos adjetivos como «meditativo», «admiración contemplativa», la «poesía del agua». Todas estas palabras nos remiten a una concepción romántica de la naturaleza. A su vez frases tales como «los hondos lagos, siempre tienen a su vera un viejo volcán apagado, que revela con el misticismo de un asceta, el despunte del sol y la muriente soledad de las tardes con su brillante policromía» (Guía Peuser 1945 311). Consideramos que esta frase es ejemplificadora del estilo de escritura utilizado en la guía, el cual es claramente poético. 
Los destinatarios de esta sección de la guía parecen ser los de una clase social mediaalta, dispuesta a comprender este lenguaje poblado de adjetivos y términos poco usuales en la cotidianeidad, cuando podríamos pensar que el objetivo de la guía podría ser meramente práctico y con un lenguaje más «llano», dado el carácter social del turismo que se declama propiciar en estos años (Núñez y Vejsbjerg 2010).

En el último párrafo de la guía de 1945 podemos observar la única mención al componente humano de la región como con tradición «indo-hispana» sin desarrollar ni profundizar sobre el tema, porque lo presenta exento de contradicciones, en una tipografía pequeña, lejos de los títulos. Lo principal, desde la gráfica de la escritura, son las materialidades por fuera de la humanidad: el agua, las piedras y el bosque: «Pero no solo tiene belleza la región de los lagos argentinos, una belleza portentosa, sin exacto parangón posible con ninguna comarca de la tierra (ya hemos definido, en líneas generales, sus puntos de contacto con Suiza). Tiene tradición. Una tradición indo-hispana-afirmada en la leyenda del aborigen y en las armas de Castilla-que ha canalizado su encanto colonial que ensoñó entre el laberinto de las montañas y los bosques, la existencia de un nuevo becerro de oro con su joyante metrópoli, la fantástica ciudad de los Césares, entre la comisura de las montañas, salpicada de bosques y de ventisqueros, de cascadas furentes y de espumosos arroyos, con sus alcázares soberbios, con tejuelas de oro y tachonados de pedrerías; una ciudad de los Césares, digna de la Bagdad de «Las mil y una noches...». (Guía Peuser 1945 313).

Ernesto Bohoslavsky (2011) propone considerar las identidades latinoamericanas por lo que niegan ser más que por lo que supuestamente tiene de homogéneo, y esto resulta revelador para el caso que nos ocupa. Patagonia sería aquello que no es pampa, Mesopotamia, Cuyo etc. Pero es algo más, es un vacío. Las fotografías que acompañan a los textos son de paisajes, no hay personas en ellas, y a diferencia de Córdoba y Mar del Plata, casi no hay rastros de urbanismo, arquitectura, o espacios culturales, en directa concordancia a los elementos elegidos para los títulos. Letras y fotos se refuerzan mutuamente crean una experiencia estética, que remite al vacío de cultura. En el caso de la Patagonia la naturaleza es la única protagonista de las fotografías.

La fotografía, como demostró Barthes (1986), puede estar vinculada al texto como «anclaje» o como «relevo». La primera sería ilustrando la información que este 
proporciona, siendo redundante, y la segunda es complementaria. En este caso podemos observar la presencia del primer tipo de vínculo entre imagen y texto, ya que se describe el Lago Frías, pero a su vez se agrega una información complementaria, que una vez más, invoca la comparación con Europa y Asia, «... conservando su estado salvaje originario, se entretejen y forman infinidad de paisajes, en los que la naturaleza ha reproducido fiords de Suecia y Noruega; lochs de Escocia, panoramas de Italia y Suiza, montañas cubiertas de nieves eternas como el Himalaya» (Guía Peuser 1945 315) la cual es recurrente en la escritura. Las palabras buscan lograr puentes de imágenes hacia paisajes ausentes en el texto, pero que en la lectura guían al lector a una experiencia más amplia. El sentido estético de la región del sur está fuera de la experiencia nacional, y esto es una diferencia en relación con los principales centros turísticos citados.

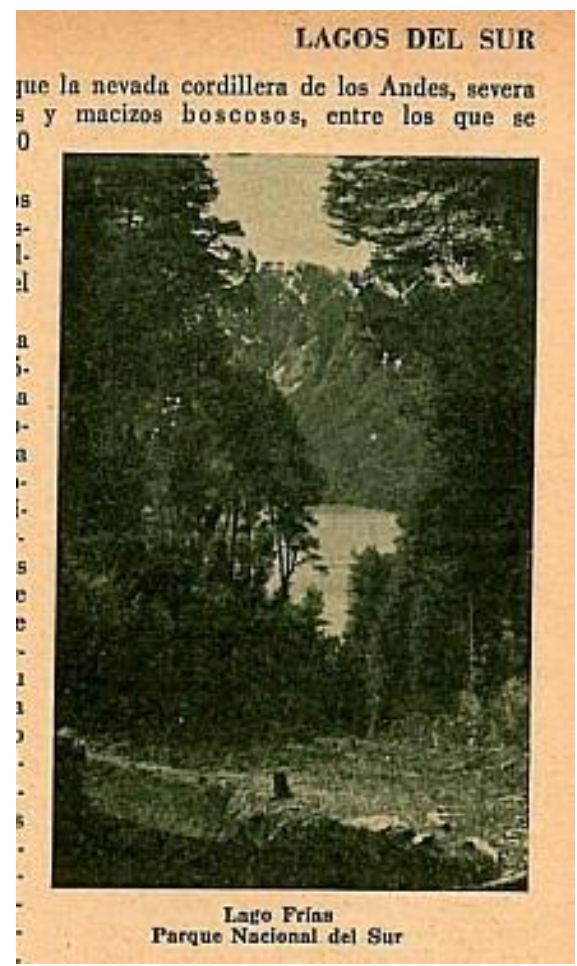

(a)

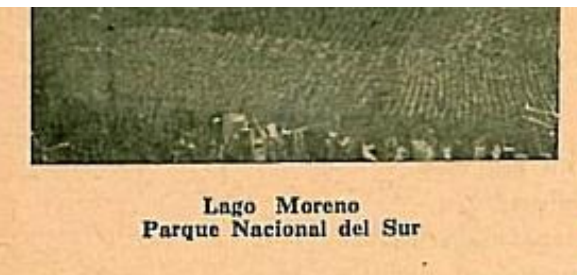

Descripción general. - La región que abarca el Parque Nacional de Nahuel Huapi reúne las más variadas y bellas manifestaciones de la naturaleza primitiva. Maravillosamente dotado, presenta una sucesión de montañas, ventisqueros, ríos, lagos, bosques, torrentes y cascadas que, conservando su estado salvaje origi. nario, se entretejen y forman infinidad de paisajes, en los que la naturaleza ha reproducido fiords de Suecia y Noruega; lochs de Escocia, panoramas de Italia y Suiza, montañas cubiertas de nieves eternas como el Himalaya.

Fig 14: Guía Peuser, 1945, 315. 
Pero, en la última guía observada, de 1955, vemos cómo se manifiesta un cambio. En los usuales párrafos descriptivos incluyen con un lenguaje más simple las obras realizadas en los últimos años: capillas, centro de esquí, escuela de artes y oficios. Ya no solo estamos frente a la presencia sublime y abrumadora de la naturaleza, aparecen señales humanas, indicadores de «civilización y progreso». Aparece el Estado como un protagonista e interventor del paisaje. Podemos pensar que aparece una nueva creencia social, como dicen Berger «lo que sabemos o lo que creemos afecta el modo en que vemos las cosas» (Berger 2013 1), ante la creencia en el Estado, cambia el «modo de ver» y, por lo tanto, lo que muestran las fotografías. Esto se manifiesta también en las imágenes que acompañan, por primera vez aparece algo más allá de la naturaleza: fotografías de la calle Mitre, la principal de San Carlos de Bariloche, su catedral y su Centro Cívico: ${ }^{7}$

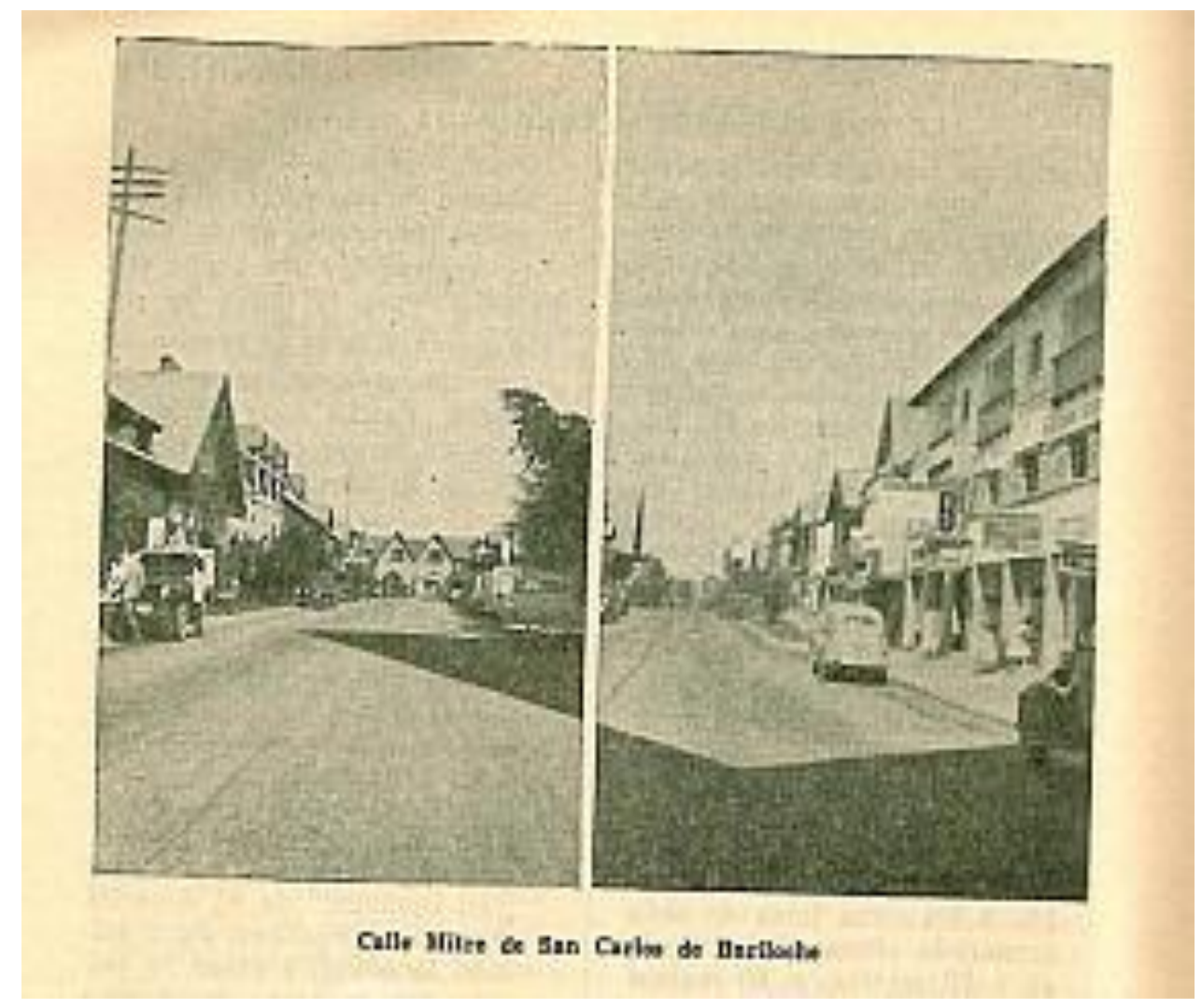

Fig 15: Guía Peuser, 1955, 410.

\footnotetext{
${ }^{7} \mathrm{Si}$ bien estas obras no son nuevas, ya que fueron construidas por la Dirección de Parques Nacionales en tiempos de Exequiel Bustillo, el Centro Cívico fue inaugurado 17 de marzo de 1940 y la catedral en 1944-es relevante mencionar su aparición en las guías.
} 


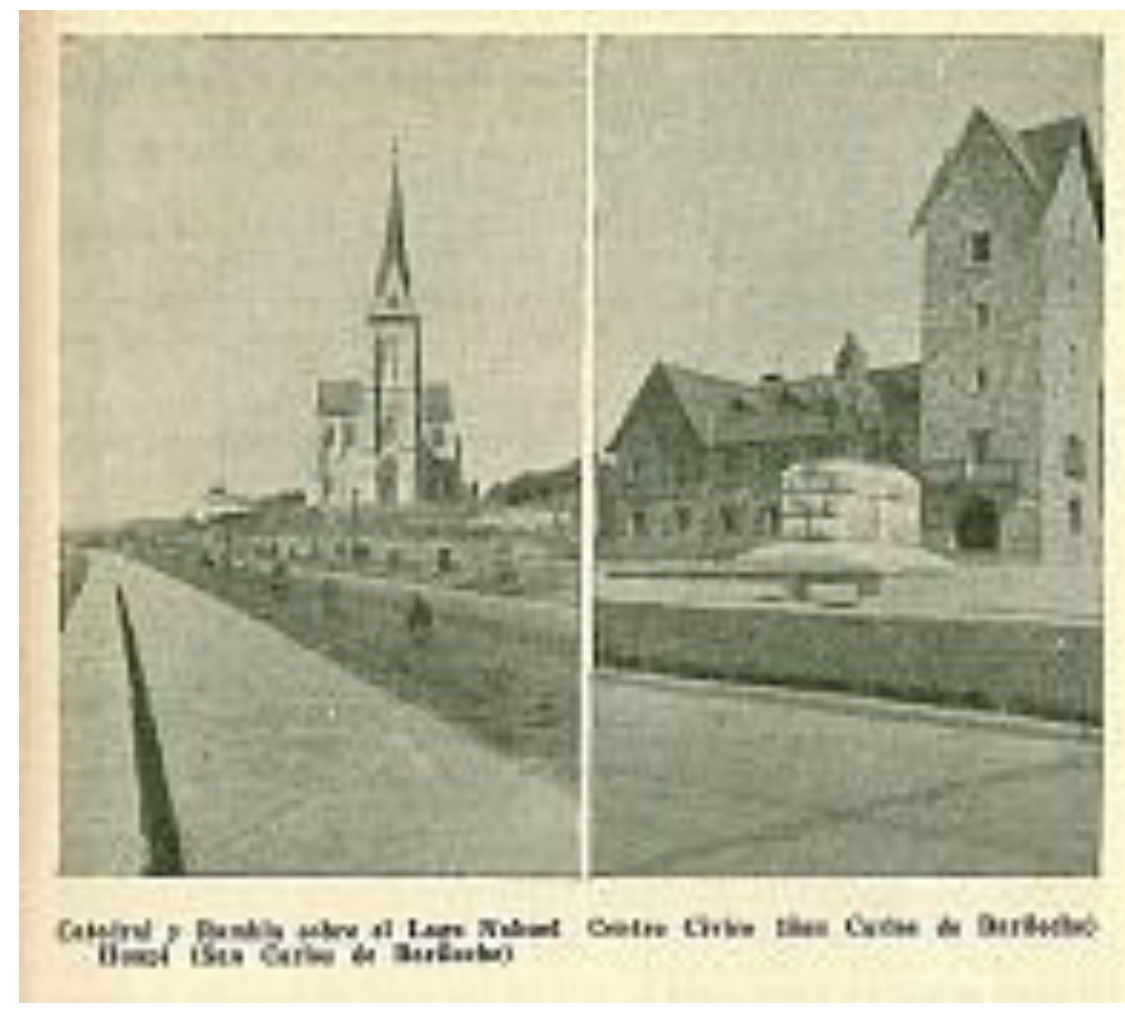

Fig 16: Guía Peuser, 1955, 413.

Tal como lo mencionamos, la zona de la cordillera patagónica se presenta como destino turístico más amplio para 1955. Aparece por primera vez la zona de San Martín de los Andes, en la provincia de Neuquén, y con ella una fotografía de árboles de la región cortados para la industria. De este modo, en el nivel de las imágenes podemos decir que se manifiesta un gran cambio cuantitativo y cualitativo: hay dos fotografías de naturaleza y cuatro de infraestructura. estas imágenes actúan a modo deíndice. Para Barthes (1990) el «yo estuve ahí» es lo que caracteriza a la fotografía. Antes que ser registro de un tiempo, la fotografía es un certificado de presencia, de un haber estado en determinado lugar. En este caso, las fotografías son utilizadas como prueba inexorable de los avances materiales que promueve el Estado en la región. Son índice de la presencia del Estado.

Las guías continúan su descripción con un apartado más orientado a lo práctico: listados de hoteles, listado de distancias en kilómetros, consejos para visitar el parque, y una sección importante destinada a la pesca: «qué y dónde» se pesca, «cómo se llega a las zonas de pesca», «lo que conviene llevar para pescar» y «como se aloja en los lugares de pesca» son algunos de los subtítulos destinados a este deporte. Podemos tomar esto como otro indicador del tipo de público al que se dirige esta guía. Por todo lo relevado nos atrevemos a afirmar que estas guías están orientadas a un turismo 
proveniente de las grandes ciudades como Buenos Aires, con un poder adquisitivo medio-alto y no a un turismo cercano. Es llamativo ver como en otras regiones suele haber un listado de cines y teatros de la zona, actividades culturales en la región y en «Los lagos del sur» se omite por completo esta información. El paisaje es paisaje vacío $\mathrm{y}$ «no cultural», autosuficiente en su belleza.

Comparando las tres guías analizadas observamos como la guía Peuser de 1950 es la única que tiene un diccionario de palabras en 4 idiomas: español, inglés, italiano y francés. Y una sección de «Turismo femenino» orientado principalmente a la moda en las viajeras, consejos sobre vestuario, de belleza, ropa para equitación etc. Continúa presente el lenguaje poético y la descripción romántica con la naturaleza, tanto en esta guía como en la de 1955, otro rasgo llamativo sobre el posible público es la aparición de la cita del pintor Emil Jackson respecto a la Patagonia, donde una vez más, Suiza es el parámetro de belleza y, al mismo tiempo, es una belleza que el arte no puede capturar. Según Jackson la pintura que pretende copiar el paisaje se ve enmudecida, imposibilitada: «Debo declarar que por primera vez en mi vida hube de deponer mi orgullo de saber pintar con la pluma todo lo que pasó por mi retina. Frente a la región del Nahuel Huapi, el asombro ahora las expresiones y no hay fantasía descriptiva capaz de superar a la realidad inmanente que el viajero tiene ante la vista...» (Guía Peuser 1955 399). Ante el paisaje imponente «cuyas bellezas subyugan a cuantos los visitan» (Guía Peuser 1955 398) como reza el subtítulo del apartado titulado «Los lagos del sur», el artista se llama al silencio.

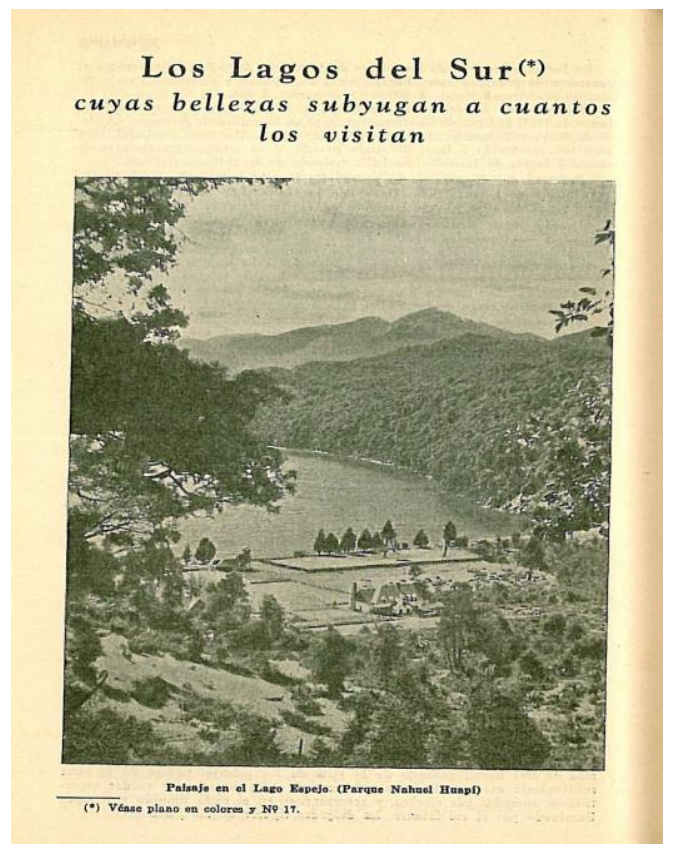

Fig 17: Guía Peuser, 1955, 398. 
Otra característica distintiva de la guía de 1950 es que es un híbrido entre las otras dos. Mantiene el lenguaje poético utilizado en las tres, y permanece la concepción esencialista de la naturaleza presente en las tres, pero comienzan a aparecer algunos rasgos de la presencia del Estado que posteriormente se verán reforzados. En este caso el Estado aparece como garante de la preservación ecológica:

\section{Los Parques Nacionales}

Trátase de extensas regiones que el Estado, con espiritu previsor, ha reserfado con el propósito de convertirlas en sagrario de su flora y fauna. Su superde Nahuel Huapi, las reservas de Copahue, y comprenden, además del parque Perito Moreno, recostados Nacional del İuazí on ln nn+ ellos sobre la cordillera patagónica, y el Paraue

Fig 18: Guía Peuser, 1950, 229.

Lo más distintivo de la guía del año 1955 es que la presentación de la región «Lagos del sur» es muy diferente a las otras dos guías analizadas en tanto se plantea otro vínculo con los ciudadanos:

\section{LAGOS DEL SUR}

Acaban de ser instituídas por el gobierno "Las Jornadas Argentinas de Par. ques Nacionales". Serán los días 4 de noviembre de cada año el punto inicial, para que se cumpla la voluntad del Poder Ejecutivo y del primer magistrado de la Nación, quien dijo que "hay que hacer factible el acceso del pueblo al conocimiento de las bellezas naturales del país". Y así se hará ahora que se se han acortado distancias y fatigas mediante la instauración de nuevas y cómodas rutas.

Cuando se habla de los lagos del Sur, un silencio emocional se apodera del espiritu. Es de tan extraordinaria belleza la región lacustre argentina, que

Fig 19: Guía Peuser, 1955, 399.

Así, la experiencia estética que se propone desde la lectura está lejos de reducirse a las fotos y debe comprenderse en el contexto general del escrito. La tipografía central del título «Los Parques Nacionales» respecto de la titulación ubicada a la derecha en «Lagos del Sur» marca lugares y relevancias diferentes.

En 1955 el territorio se complejiza y la propia tipografía lo refleja en la modalidad de la escritura.

El peronismo ha sido caracterizado como un movimiento que democratizó el goce. En este sentido, fue clara la propuesta del acceso de las clases medias-bajas a 
lugares de vacaciones como Mar del Plata y, como vemos en este párrafo, las intenciones de que también accedan a esta región. Sin embargo, con lo que respecta a la descripción de la naturaleza y el estilo de escritura del texto se mantienen las características poéticas antes mencionadas, aparecen frases tales como: el «silencio emocional», los «contornos singulares del agua, ora mansos, ora bravíos» (Peuser 1955 200). Respecto a la comparación con Suiza, esta es mencionada pero de modo superador: «mal podría llamarse Suiza Argentina», justificando que la belleza de nuestra región es porque «no hay nada que resista el parangón ni nada que se le asemeje». Si antes el país europeo servía para validar y comparar la belleza, ahora es un parámetro que ya hemos sobrepasado, «importamos» un paisaje extranjero y lo mejoramos.

Este lenguaje, la cita a Jackson, la descripción de la naturaleza, parecen contradictorios con el objetivo antes planteado de que sea una zona más «accesible al pueblo». Más adelante dice «la región de los lagos del Sur ha formado ya conciencia mundial. Se la conoce en el extranjero como un paraíso terrenal que ha de ser frecuentado por todos: hombres de letras, pintores, mercaderes, banqueros, y millonarios» (Peuser, 1955, 201). Podemos ver claramente como en este párrafo no se presentan oficios propios del turismo popular antes invocado.

\section{Conclusiones}

La construcción del pasado se hace desde el presente y hacia al futuro. Hacemos historiografía teniendo siempre latente la promesa de futuro. Vamos hacia atrás para ir hacia adelante. En nuestro caso, revisamos las denominaciones dominantes de la Patagonia, condensadas en las guías de turismo Peuser de 1945, 1950 y 1955, vimos cómo a lo largo de esos 10 años no hubo cambios sustanciales en la construcción que se propone desde el arte institucional de la imagen de la naturaleza, la cual estuvo basada en una estetización del paisaje que, sin dudas, estaba a su vez atravesada por un proyecto político. Pero sí pudimos observar un intento por modernizar la Patagonia a través de la intervención del Estado mediante nuevas obras y una inclusión al pueblo quizá más a nivel material que simbólico.

El turismo nacional parece de diferentes países, un país vivido y recorrido, cercano, con historia, que se configura como destino del turismo e incluso del 
desarrollo. Y un país vacío, para la contemplación, donde la naturaleza es la marca de lo que debe ser. Donde el paisaje no intervenido es lo nacional. Un paisaje sin habitantes fijos, y que se dibuja al servicio del otro país, el que está vivido.

El discurso gráfico muestra con mayor crudeza que el resto de las fuentes, la diferencia, y el turismo resulta en la actividad natural del espacio vacío y majestuoso.

A través de este trabajo invitamos a pensar de qué otros modos podemos abordar el estudio de los materiales turísticos y sus clichés identitarios que atraviesan las ciudades argentinas. ¿Cómo construir las identidades de nuestros espacios, más allá de la historia colonial que los atraviesa?. En este caso, no solo hemos tomado la guía de turismo en su aspecto textual sino hemos visto como hablan, fundamentalmente, sus imágenes. No solo el qué se dice y sino el cómo se dice. Y fue en sus fotografías, en sus mapas y diseños, en su modo de escritura donde encontramos las claves más importantes para la definición de la identidad de la ciudad de San Carlos de Bariloche: donde prevalece un imaginario de belleza natural romántica, esencial, inmutable, un lugar de vacaciones comparable con el paisaje europeo, como lugar turístico para la clase media-alta, como un lugar en el cual es más importante la exuberancia de la naturaleza que el factor humano y cultural.

Una Patagonia que, según muestran las guías Peuser en el transcurso de estos años, poco a poco pretende acercarse al pueblo pero, aún con avances estructurales, descuida el vínculo simbólico.

Forma y contenido están intrínsecamente unidos. No basta enunciar, no basta que el contenido pretenda ser accesible a lo popular, también debe serlo en sus modos y recursos. He ahí otro posible debate abierto a futuro: ¿Qué formas y estilos serían aquellos más adecuados para que el público lector de las guías Peuser sea parte de la propuesta de turismo social, accesible a los sectores populares?

\section{Obras citadas}

\section{Fuentes}

Guía de turismo Peuser, Buenos Aires, Editorial Peuser S. A., 1945.

Guía de turismo Peuser, Buenos Aires, Editorial Peuser S. A., 1950. 
Guía de turismo Peuser, Buenos Aires, Editorial Peuser S. A., 1955.

Control de Estado de la Presidencia de la Nación, La Nación Argentina Justa Libre Soberana, Buenos Aires, Editorial Peuser S. A., 1950. Disponible en http://www.ruinasdigitales.com/revistas/PatriaJustaSoberana.pdf

\section{Bibliografía}

Arias, Mario, «Tensiones en los debates parlamentarios en torno a la provincialización de los Territorios Nacionales durante el primer peronismo». Quinto Sol, Vol. 14, pp. 2010. 103-124, Disponible en: https://cerac.unlpam.edu.ar/index.php/quintosol/article/view/26

Barthes, Roland, «El mensaje fotográfico»; adapt. de Barthes Roland, en Lo obvio y lo obtuso, Barcelona, Paidós, 1986.

- La cámara lúcida, nota sobre la fotografía, Barcelona, Paidós, 1990.

Benjamin, Walter, «La obra de arte en la época de su reproductibilidad técnica», en Conceptos de filosofía de la historia, Buenos Aires, Agebe, 2010.

Berger, John, Modos de ver, Barcelona, Gustavo Gili, 2013.

Bessera, Eduardo, «Exequiel Bustillo y la gestión de los Parques Nacionales. Una aproximación a su concepción de las fronteras como áreas naturales protegidas», en P. Navarro y W. Delrio (eds.), Cultura y espacio: Contribuciones a la diacronización del corredor Norpatagonia Araucanía, Argentina, Universidad Nacional de Río Negro-Instituto de Investigaciones en Diversidad Cultural y Procesos de Cambio, 2011, pp. 115-125.

Bohoslavsky, Ernesto, «Qué es América Latina? El nombre, la cosa y las complicaciones para hablar de ellos», en Bohoslavsky, Ernesto; Geoghegan, Emilce y González, María Paula (coords.), Los desafíos de investigar, enseñar y divulgar sobre América latina. Actas del taller de reflexión TRAMA, Los Polvorines, Universidad Nacional de General Sarmiento, 2011.

Cicalese, Guillermo, La Nación Argentina justa, libre, soberana: un atlas nacional para representar el mundo peronista. Un ensayo de interpretación, Mar del Plata, Universidad Nacional de Mar del Plata, 2018.

Cruder, Gabriela, «La biblioteca infantil General Perón: una propuesta comunicacional para la formación ciudadana de los niños», Revista Questión, 2011.

Girbal Blacha, Noemí, «En la Argentina peronista "Los únicos privilegiados son los niños" (1946-1955). La doctrina desde la Biblioteca Infantil "General Perón”», Historia Contemporánea (Universidad del País Vasco) $\mathrm{n}^{\circ}$ 50, 2015. https://www.ehu.eus/ojs/index.php/HC/article/view/14145

Iuorno, Graciela, «La provincialización de Río Negro. Interregno y conflicto de intereses nacionales y locales», en Ruffini, M. y Masera, R. F. (Coords.) Horizontes en perspectiva. Contribuciones para la historia de Río Negro, 1884-1955, Viedma, Legislatura de la Provincia de Río Negro. 2007, pp. 391405 .

Lois, Carla, «El mapa, los mapas, propuesta metodológica para abordar la pluralidad y la inestabilidad de la imagen cartográfica», Graficando, N. ${ }^{0}$ 11, junio, 2015. 
Macord, Darío y César Tcach (Eds.), La invención del peronismo en el interior del país, Buenos Aires, UNL, 2003.

Méndez Laura y Jorge Muñoz Sougarret, «Alianzas sectoriales en clave regional. La Norpatagonia argentino-chilena entre 1895 y 1920», en Nicoletti, M. A. y Núñez, P. (comps.), Araucanía-Norpatagonia: La territorialidad en debate, San Carlos de Bariloche- Argentina, IIDYPCA (Universidad Nacional de Río Negro), 2013, pp. 152-167.

Navarro Floria, Pedro, «Territorios marginales: los desiertos inventados latinoamericanos. Representaciones controvertidas, fragmentadas y resignificadas», en Trejo Barajas, Dení (coord.), Los desiertos en la historia de América, una visión multidisciplinaria, México, Universidad Michoacana de San Nicolás de Hidalgo, Universidad de Coahuila, 2011.

Núñez, Paula, «Municipio y provincias. Una indagación en torno a la dinámica relacional a partir de un estudio de caso», Territorios, Vol. 16-17, 2007, pp. 207224. Disponible en: https://www.redalyc.org/articulo.oa?id=35701711

- $\quad$ Memorias fragmentadas entre lo alpino y lo andino. El refugio Italia y las percepciones sobre el poblamiento en la región del Nahuel Huapi», Estudios Trasandinos, Vol. 18, N. ${ }^{\circ}$ 1, 2013, pp. 101-120. Disponible en: https://dialnet.unirioja.es/descarga/articulo/7302075.pdf.

- "The peronist incomplete reconstruction of the border: An analysis of the Nahuel Huapi región», Argentina (1946-1955), Estudios Fronterizos, Vol. 16, N. ${ }^{\circ} \quad 31, \quad$ pp. 56-73, 2015. Disponible en: https://www.researchgate.net/profile/Paula Nunez3/publication/273119855 The peronist incomplete reconstruction of the border An analysis of the Nahuel Huapi region Argentina 19461955/links/54f729760cf210398e92195e/The-peronist-incompletereconstruction-of-the-border-An-analysis-of-the-Nahuel-Huapi-regionArgentina-1946-1955.pdf.

- y Martín Núñez, «Conocer y construir la naturaleza en el sur argentino». En Silva y Salvatico filosofía e historia da ciencia no cono sur. (ntr), Porto Alegre, Mentes editorial, 2012.

Núñez, Paula y Laila Vejsbjerg, «El turismo, entre la actividad económica y el derecho social: el Parque Nacional Nahuel Huapi, 1934-1955», Estudios y Perspectivas en Turismo, Vol. 19, N. ${ }^{\circ}$ 6, noviembre 2010, pp. 930-945. Disponible en: https://www.redalyc.org/pdf/1807/180717577004.pdf.

Pastoriza, Elisa, «Memoria obrera y turismo. Las vacaciones populares durante el Primer peronismo», en XIV Jornadas Interescuelas/Departamentos de Historia. Departamento de Historia de la Facultad de Filosofía y Letras, Mendoza, Universidad Nacional de Cuyo, 2013.

- «El turismo social en la Argentina durante el primer peronismo. Mar del Plata, la conquista de las vacaciones y los nuevos rituales obreros, 1943-1955», Nuevo Mundo Mundos Nuevos, Debates, 2008.

- y Pedetta, Marcelo, «"Lo que el pueblo necesita”. Turismo social y Peronismo. Argentina, 1945-1955», Études Caribéennes, Vol. 13-14, 2009. Disponible en: https://journals.openedition.org/etudescaribeennes/3767.

Picone, María de los Ángeles, «La idea de turismo en San Carlos de Bariloche a través de dos guías (1938)», Estudios y Perspectivas en Turismo, N. ${ }^{\circ}$ 22, 2013, pp. 
198-215.

Disponible

en:

https://dialnet.unirioja.es/servlet/articulo?codigo $=5131430$.

Piglia, Melina y Elisa Pastoriza, «La construcción de políticas turísticas orientadas a los sectores medios durante el primer peronismo: Argentina. 1946-1955», Licere, Vol. 20, N. ${ }^{\circ}$ 1, marzo de 2017, pp. 411-452. Disponible en: https://ri.conicet.gov.ar/handle/11336/34671.

Ruffini, Martha, «Peronismo, Territorios Nacionales y ciudadanía política. Algunas reflexiones en torno a la provincialización », Revista Avances del Cesor, N ${ }^{\circ}{ }^{5}$, 2005, pp. 132-148. Disponible en: http://biblioteca.clacso.edu.ar/Argentina/cehepycuncoma/20110414122415/Ruffini.pdf.

Silvestri, Graciela, «Postales argentinas», en Altamirano, Carlos (ed.), La Argentina en el siglo XX, Bernal, Ariel-Universidad Nacional de Quilmes, 1999.

Torre, Juan C. y Elisa Pastoriza, «La democratización del bienestar», en Torre, J. C. (dir.), Nueva historia argentina, t. VII, Buenos Aires, Sudamericana, 2002.

Troncoso, Claudia y Carla Lois, «Políticas turísticas y peronismo. Los atractivos turísticos promocionados en Visión Argentina (1950)», Pasos: Revista de Turismo y Patrimonio Cultural, Vol. 2, N. 2, 2004, pp. 281-294. Disponible en: http://www.pasosonline.org/Publicados/2204/PASOSo4.pdf\#page=137. 